\title{
CES
}

COOPERATIVISMO E ECONOMÍA SOCIAL

Núm. 43 (2020-2021), páxs. 149-174

ISSN: 2660-6348

\section{RÉGIMEN APLICABLE A LAS AMPLIACIONES DE CAPITAL EN LAS SOCIEDADES LABORALES}

\author{
REGIME APPLICABLE TO CAPITAL \\ INCREASES IN LABOR COMPANIES
}

\author{
RAFAEL JORDÁ GARCÍA*
}

Recepción: 16/06/2021 - Aceptación: 7/10/2021

Abogado. Profesor Asociado de Derecho Mercantil (Acreditado Contratado Doctor) Universidad de Murcia. Profesor colaborador de la Cátedra de Economía Social de la Universidad de Murcia. Dirección de correo electrónico: rafajorda@um.es 


\title{
RESUMEN
}

Las sociedades laborales son reconocidas como entidades de economía social, si bien son por la forma sociedades de capital. Se les aplican las especialidades previstas en la Ley de Sociedades Laborales, pero también las normas de la Ley de Sociedades de Capital en lo que no contradigan su régimen de sociedades laborales. La ejecución de una ampliación de capital puede afectar al reparto del capital social, cuestión relevante para poder mantener la calificación de sociedad laboral, por los requisitos de participación mínima y máxima de sus trabajadores en el capital social. El presente trabajo analiza las normas aplicables a las sociedades laborales en las ampliaciones de capital, contenidas tanto en su ley reguladora, como en la Ley de Sociedades de Capital por falta de regulación en la Ley de sociedades laborales. De dichas normas analizaremos con más profundidad las que afecten o puedan afectar a la participación de los socios en el capital social.

Palavras Chave: Sociedades Laborales, Ampliación de capital.

\begin{abstract}
Labor companies are recognized as social economy entities, although formally are capital companies. The specialties provided for in the Labor Companies Law apply to them, but the rules of the Capital Companies Law also apply to the Labor Companies, as far as they do not contradict their Labor Companies Law. The execution of a capital increase may affect the distribution of share capital, relevant issue to be able to maintain the qualification of labor society, due to the minimum and maximum participation requirements of its workers in the capital stock. This work analyzes the rules applicable to labor companies in capital increases, contained both in its regulatory law and in the Capital Companies Law due to lack of regulation in the Labor Companies Law. Of these rules we will analyze in more depth those that affect or may affect the participation of the partners in the capital stock.
\end{abstract}

Keyworlds: Labor Companies, Capital Increase. 
SUMARIO: I. LAS SOCIEDADES LABORALES, ENTIDADES DE ECONOMÍA SOCIAL Y SOCIEDADES DE CAPITAL. II. CUESTIÓN PREVIA. REPARTO DEL CAPITAL SOCIAL EN LAS SOCIEDADES LABORALES. 1. Reparto del capital social entre los socios. 2. Clases de acciones y participaciones. 3. Doble control de legalidad: Registro Mercantil y Registro Administrativo. III. LAS NORMAS SUSTANTIVAS EN MATERIA DE AMPLIACIÓN DE CAPITAL APLICABLES A LAS SOCIEDADES LABORALES PREVISTAS EN SU LEY REGULADORA O EN LA LEY DE SOCIEDADES DE CAPITAL. 1. Órgano competente, propuesta de ampliación y convocatoria. 2. Quorums y mayorías para aprobar un aumento de capital 3. Modalidades del aumento del capital. Tipos de aportaciones. 4. Aumento incompleto. 5. Ejecución de la ampliación de capital. IV. ESPECIAL REFERENCIA A LOS DERECHOS DE SUSCRIPCIÓN Y ASUNCIÓN PREFERENTE EN LAS SOCIEDADES LABORALES. V. OTRAS CUESTIONES EN MATERIA DE AMPLIACIÓN DE CAPITAL. 1. Prohibición de transmisión de acciones o participaciones objeto de ampliación. 2. Otras referencias: asistencia financiera y reserva especial. VI. CONSIDERACIONES FINALES. VII. BIBLIOGRAFIA.

SUMMARY: I. LABOR COMPANIES, SOCIAL ECONOMY ENTITIES AND CAPITAL COMPANIES. II. PREVIOUS QUESTION. DISTRIBUTION OF SHARE CAPITAL IN LABOR COMPANIES. 1. Distribution of capital among the partners. 2. Classes of shares and participations. 3. Double legality control: Commercial Registry and Administrative Registry. III. THE SUBSTANTIVE RULES REGARDING CAPITAL INCREASE APPLICABLE TO LABOR COMPANIES PROVIDED FOR IN THEIR REGULATORY LAW OR IN THE CAPITAL COMPANIES $L A W$. 1. Competent body, increase proposal and call. 2. Quorums and majorities to approve a capital increase 3. Modalities of the capital increase. Types of contributions. 4. Incomplete increase. 5. Execution of the capital increase. IV. SPECIAL REFERENCE TO THE RIGHTS OF SUBSCRIPTION AND PREFERRED ASSUMPTION IN LABOR COMPANIES. V. OTHER ISSUES REGARDING CAPITAL INCREASE. 1. Prohibition of transfer of shares or participations subject to expansion. 2. Other references: financial assistance and special reserve. VI. FINAL CONSIDERATIONS. VII. BIBLIOGRAPHY.

\section{LAS SOCIEDADES LABORALES, ENTIDADES DE ECONOMÍA SOCIAL Y SOCIEDADES DE CAPITAL}

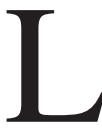

as sociedades laborales son sociedades de capital por su forma y por tanto les son aplicables las normas relativas a las sociedades anónimas y limitadas $^{1}$, en todo lo que la Ley 44/2015, de 14 de octubre, de Sociedades Laborales y Participadas (LSLP) no regule expresamente con carácter diferenciador ${ }^{2}$.

\footnotetext{
1 Exposición de Motivos de la Ley 44/2015, de 14 de octubre, de Sociedades Laborales y Participadas.

2 Nos centramos en las sociedades laborales y no en las sociedades participadas por trabajadores, al ser estas, como señala FARIAS BATLLE, M., ("Sociedad participada por los trabajadores. A propósito del régimen de la Ley 44/2015, de sociedades laborales y participadas", $R d S$, núm. 53, 2018, p. 20), una figura carente de una regulación legal propiamente dicha y que de mantenerse en estos términos será, en el mejor de los casos, inútil y en el más probable, generadora de incertidumbre e inseguridad
} 
Desde la aprobación de la primera Ley de Sociedades Laborales de $1997^{3}$, hasta la vigente de 2015, han sido numerosas las reformas legislativas que han afectado, directa o indirectamente a las sociedades anónimas y limitadas, debiendo destacar con mucho el Texto Refundido de la Ley de Sociedades de Capital, aprobado por el Real Decreto Legislativo 1/2010, de 2 de julio (LSC), sin olvidar ni omitir, la Ley 22/2003, de 9 de julio, concursal; la Ley 2/2007, de 15 de marzo, de sociedades profesionales; o la Ley $3 / 2009$, de 3 de abril, sobre modificaciones estructurales de las sociedades mercantiles ${ }^{4}$. Ello exigió una adecuación de la LSLP al nuevo marco normativo y una sistematización de sus normas más acorde, en particular, con la establecida en la LSC, que en la medida que había refundido en un mismo texto la regulación de la sociedad anónima y de la sociedad de responsabilidad limitada, ha supuesto revisar cuando las soluciones jurídicas para las sociedades laborales anónimas y de responsabilidad limitada, son comunes o diferenciadas.

Las sociedades laborales también son, por sus fines y principios orientadores, entidades de la economía social, como señala explícitamente la Ley 5/2011, de 29 de marzo, de economía social y, por tanto, como señala la Exposición de Motivos de la LSLP, deben ser acreedoras de sus políticas de promoción, entre las que figura el mandato a los poderes públicos de crear un entorno que fomente el desarrollo de iniciativas económicas y sociales en el marco de la economía social. Con este objetivo, la disposición adicional séptima de esta ley ordenaba al Gobierno que remitiera a las Cortes un proyecto de ley que actualizase y revisase la Ley 4/1997, de 24 de marzo, de Sociedades Laborales.

La LSLP mejora su régimen jurídico con los objetivos de fomentar la participación de los trabajadores en las empresas, facilitando su acceso a la condición de socios, al tiempo que se incorporan nuevas medidas para asegurar el control de la sociedad por parte de los trabajadores, aumentar la utilidad de las sociedades laborales y su preferencia por parte de los emprendedores. Pretende fortalecer su vertiente empresarial y consolidar el carácter estable y no coyuntural de este modelo empresarial, y reestructura el articulado eliminando preceptos superfluos e incorporando otros necesarios ${ }^{5}$.

\footnotetext{
jurídica, por lo que resulta, en consecuencia, más que recomendable que la participación financiera de trabajadores en las empresas en España se fomente en una nueva Ley que, derogando el Capítulo III LSLP, sea elaborada por consenso de todas las fuerzas parlamentarias y previa consulta con los agentes sociales, sobre todo con las organizaciones que representan a la patronal y a los trabajadores.

3 Respecto a la regulación de las sociedades laborales de 1997, nos remitimos al comentario próximo a su entrada en vigor de MAGRO SERVET, V. "La sociedad de responsabilidad limitada laboral: un modelo societario en progreso", Revista de Derecho Mercantil, num.230, 1998, pp. 1-14.

4 Como refiere expresamente la Exposición de Motivos de la LSLP

5 Exposición de Motivos de la LSLP.
} 
Las sociedades laborales persiguen tanto el interés colectivo de sus integrantes como el interés general. Ambos reflejados, como señala la Exposición de Motivos de la LSLP, en que estas se convierten en un "método de autoempleo colectivo por parte de los trabajadores"6.

Los principios de la economía social, recogidos en el art. 4 de la Ley 5/2011, de 29 de marzo, de Economía Social (LES) ${ }^{7}$, son aplicables a las sociedades laborales, como se reconoce explícitamente en el art. 5 LES y en la propia LSLP, en su Exposición de Motivos, por remisión a la propia LES.

En las sociedades anónimas y limitadas laborales, conviven la relevancia del autoempleo como faceta de la economía social y las normas de las sociedades de capital en todo aquello que no esté regulado expresamente por la LSLP. En lo que nos afecta, las sociedades laborales deben cumplir, para adquirir la calificación administrativa como "laborales", los requisitos establecidos en cuanto a participación mayoritaria de los trabajadores en el capital social, sin que ninguno de ellos exceda de un tercio del mismo, cuestión en la que puede incidir una ampliación de capital. Al mismo tiempo, la pretensión de la participación de los trabajadores en las sociedades laborales y las medidas de fomento para potenciar dicha participación pueden, en ocasiones, pasar por una ampliación de capital.

Aunque las sociedades laborales sean entidades de economía social, se encuentran afectadas por la normativa de las sociedades de capital donde rigen principios precisamente de carácter capitalista relativos a la participación en los beneficios y por tanto que pueden culminar en la maximización de éste ${ }^{8}$.

\footnotetext{
6 No hemos de olvidar el reconocimiento constitucional en el artículo 129.2 de la Constitución Española de 1978, que ordena a los poderes públicos la promoción de las diversas formas de participación en la empresa y el establecimiento de las medidas que faciliten el acceso de los trabajadores a la propiedad de los medios de producción. Se da a los trabajadores "la posibilidad de aumentar a largo plazo su patrimonio de manera sencilla, lo cual permite añadir recursos complementarios para vivir después de dejar de trabajar". Vid. Exposición de Motivos de la LSLP, que añade que "los trabajadores a los que se permite participar en los resultados de la empresa sienten que se les tiene más en cuenta por su contribución a los resultados obtenidos por la empresa".

7 Vid. AA.VV. Economía Social y Economía Sostenible, Dir. ALFONSO SÁNCHEZ, R., Aranzadi, Cizur Menor, 2010.

8 En las sociedades de capital, las medidas de gobierno corporativo pretenden que las sociedades no tengan una visión cortoplacista buscando el mayor beneficio de cada anualidad, sino que socios y administradores se preocupen por la continuidad de la sociedad en el largo plazo. En tal sentido, HERNANDO CEBRIÁ, L., "Los acuerdos de la Junta General de las sociedades de capital y el interés social: impugnación y otras consideraciones en el entorno de la crisis económica", Revista Jurídica del Notariado, núm. 85, enero-marzo 2013, pp. 13-14; partiendo de la evolución de las doctrinas contractualista e institucionalista en torno al interés social, considera que la creación de valor para el accionista fue corregida, en parte, por la necesidad de maximización del valor de la acción de forma sostenida en el largo plazo, conjugando el interés común de los socios con el interés social, entendido como interés de la sociedad, como institución autónoma.
} 
Existen sin duda otros caracteres, en las sociedades laborales, que permiten dar cierta consistencia al principio de primacía de las personas y del fin social sobre el capital, que se concrete en una gestión autónoma y transparente, democrática y participativa. Dichas herramientas, entre otras, son la dotación obligatoria de la reserva especial (art. 14 LSLP) o la dispersión del accionariado como fórmula para evitar la distorsión del juego de las mayorías en la toma de decisiones de la sociedad.

Pero aunque se pueda argumentar que por los privilegios otorgados a los trabajadores se "prioriza la toma de decisiones más en función de las personas y sus aportaciones de trabajo y servicios prestados a la entidad o en función del fin social" ello no elimina totalmente la diferenciación de derechos en función de las aportaciones al capital social ni conlleva que la aplicación de los resultados obtenidos de la actividad económica lo sea principalmente en función al trabajo aportado y servicio o actividad realizada por los socios al fin social objeto de la entidad 9 .

Por último, respecto al principio previsto en el art. 4 c LES, de "promoción de la solidaridad interna y con la sociedad, que favorezca el compromiso con el desarrollo local, la igualdad de oportunidades entre hombres y mujeres, la cohesión social, la inserción de personas en riesgo de exclusión social, la generación de empleo estable y de calidad, la conciliación de la vida personal, familiar y laboral y la sostenibilidad", solo podemos entender directamente aplicable a las sociedades laborales la generación de empleo de calidad, siendo todas las demás medidas de carácter voluntario por aplicación de los principios de responsabilidad social corporativa ${ }^{10}$.

En definitiva, la generación de autoempleo y la participación de los trabajadores en el capital y en la gestión de la sociedad permiten configurar a las sociedades laborales como entidades de economía social, cuestión que no excluye el análisis de la normativa aplicable a las sociedades de capital, en nuestro estudio en materia de ampliaciones de capital y sus distintas finalidades, previstas en la LSC, por las

\footnotetext{
9 Pese a ello, como refiere MORGADO PANADERO, P., "Las empresas de Economía Social y el Derecho del Trabajo", Rev. Relaciones Laborales, nº 18 , quincena 23 sept. al 8 de oct. 2002, la característica fundamental que diferencia a una empresa que adopta una entidad jurídica encuadrada en la Economía Social de las empresas tradicionales es que, mientras en éstas el trabajo y el capital suelen estar separados, siendo capital lo que aportan los socios y contratando a personas ajenas para la prestación de servicios, en las empresas de Economía Social el trabajo es la principal aportación de los socios, que se acompaña de la de capital, de un modo secundario".

10 Por todos, LIZCANO, J.L., "Buen gobierno y responsabilidad social corporativa", Partida doble, $n^{\circ} 182$, noviembre 2006, pp. 20-35, señala que el buen gobierno corporativo va unido a la responsabilidad social corporativa que no se constriñe a la maximización del beneficio para el accionista y amplía el espectro de sus beneficiarios a los distintos grupos de interés, los stakeholders, entre los que se encuentran los propios trabajadores.
} 
implicaciones que las mismas pueden tener en el régimen de las sociedades laborales y de los requisitos que estas deben cumplir.

\section{Cuestión PREVIA. Reparto DEL CAPITAL SOCIAL EN LAS SOCIEDADES LABORALES}

\section{Reparto del capital social entre los socios}

Es indudable que una ampliación de capital puede modificar el porcentaje de participación de los socios, en el caso de que no todos ellos suscriban y desembolsen su parte proporcional, cuestión relevante en las sociedades laborales donde el reparto del capital social debe cumplir determinados requisitos.

El art. 1.2 LSLP señala que podrán obtener la calificación de «Sociedad Laboral» las sociedades anónimas o de responsabilidad limitada que cumplan los siguientes requisitos ${ }^{11}$ :

(a) Que al menos la mayoría del capital social sea propiedad de trabajadores que presten en ellas servicios retribuidos de forma personal y directa, en virtud de una relación laboral por tiempo indefinido ${ }^{12}$,

(b) Que ninguno de los socios sea titular de acciones o participaciones sociales que representen más de la tercera parte del capital social, si bien se amplían las excepciones a dicha regla general ${ }^{13}$. En los supuestos de transgresión sobrevenida de los límites que se indican en este apartado y en la letra a) anterior, la sociedad estará obligada a acomodar a la ley la situación de sus

11 Vid. LAZARO SÁNCHEZ, E., Calificación y descalificación de sociedades laborales: coordinación entre el Registro Administrativo y el Registro Mercantil, La Ley Mercantil, núm. 36, mayo 2017,

12 No obstante, como señala, CAÑABATE POZO, R., "Consideraciones sobre el nuevo régimen jurídico de las sociedades laborales: el derecho de separación", Revista Aranzadi Doctrinal, num.10, 2017, p.p. 1-33, p. 9, la mayoría de capital no siempre está vinculada al control de la sociedad, al menos en las sociedades de responsabilidad limitada, de conformidad con lo dispuesto en el artículo 188.1 LSC. Para, ANDREU MARTÍ, M.M., "Capítulo I. La sociedad laboral del siglo XXI. Significado y configuración", en AA.VV. El régimen jurídico de las sociedades laborales, Aranzadi, Cizur Menor, 2017, pp. 27-48, p. 39, resulta criticable que nuestro legislador no siguiera la propuesta de CONFESAL que distinguía según que las acciones o participaciones fueran de clase laboral o general; exigiendo que las primeras confirieran los mismos derechos ya fueran económicos o políticos.

13 La primera excepción es que la sociedad laboral se constituya inicialmente por dos socios trabajadores con contrato por tiempo indefinido, en la que tanto el capital social como los derechos de voto estarán distribuidos al cincuenta por ciento, con la obligación de que en el plazo máximo de treinta y seis meses se ajusten al límite general establecido, y la segunda, cuando se trate de socios que sean entidades públicas, de participación mayoritariamente pública, entidades no lucrativas o de la economía social, en cuyo caso la participación podrá superar dicho límite, sin alcanzar el cincuenta por ciento del capital social. 
socios, en el plazo de dieciocho meses a contar desde el primer incumplimiento.

(c) Que el número de horas-año trabajadas por los trabajadores contratados por tiempo indefinido que no sean socios no sea superior al cuarenta y nueve por ciento del cómputo global de horas-año trabajadas en la sociedad laboral por el conjunto de los socios trabajadores.

Si fueran superados los límites previstos en este apartado (c), la sociedad deberá alcanzarlos, de nuevo, en el plazo máximo de doce meses ${ }^{14}$. Asimismo, se flexibiliza el marco de contratación de trabajadores no socios y los plazos de adaptación en los supuestos de transgresión de los límites de capital y contratación de trabajadores no socios exigidos para no perder la condición de sociedad laboral ${ }^{15}$.

Pero, la superación de los límites de participación expuestos y las circunstancias que originen dicha situación, así como su adaptación posterior a la ley, deberán ser comunicadas al Registro de Sociedades Laborales, en el plazo de un mes desde que se produzcan, a los efectos previstos en el apartado 2 del artículo 15 de la presente ley, relativo a la pérdida de la condición de sociedad laboral ${ }^{16}$. La descalificación como laboral conllevará la pérdida y el reintegro de los beneficios y ayudas públicas, adquiridos como consecuencia de su condición de sociedad laboral desde el momento en el que la sociedad incurra en la causa de descalificación (art. 15.5 LSLP) ${ }^{17}$.

Para la regularización de los límites establecidos, una ampliación de capital puede ser un instrumento para conseguir que la mayoría del capital social siga siendo propiedad de los trabajadores, para diluir a aquel que tenga una participación superior a un tercio del capital social o para aumentar el número de trabajadores contratados por tiempo indefinido que sean socios (admitiendo como tales a los que no lo son).

\footnotetext{
${ }^{14}$ No computará para el cálculo de este límite el trabajo realizado por los trabajadores con discapacidad de cualquier clase en grado igual o superior al treinta y tres por ciento.

${ }^{15}$ El órgano del que dependa el Registro de Sociedades Laborales podrá conceder hasta dos prórrogas, por un plazo máximo de doce meses cada una, siempre que se acredite en cada solicitud de prórroga que se ha avanzado en el proceso de adaptación a los límites previstos. El plazo de adaptación en los casos de subrogación legal o convencional de trabajadores será de treinta y seis meses, pudiendo solicitarse igualmente las prórrogas previstas en este apartado.

16 Incluso, los Estatutos sociales podrán establecer como causa de disolución la pérdida de la condición de «Sociedad Laboral» de la sociedad (art. 15.6 LSLP)

17 Respecto, no solo al procedimiento para la obtención de la condición de sociedad laboral, sino también respecto a la pérdida de tal condición, vid. LAZARO SÁNCHEZ, E., "Calificación y descalificación de sociedades laborales: coordinación entre el Registro Administrativo y el Registro Mercantil, La Ley Mercantil, núm. 36, mayo 2017, p. 2 y ss.
} 


\section{Clases de acciones y participaciones}

El artículo 5 LSLP mantiene la dualidad de las clases de acciones y participaciones hasta ahora existentes: laboral y general ${ }^{18}$, en función de que su propietario sea o no socio trabajador y, con el fin de facilitar la gestión y transmisión de las mismas, se exige que sean de igual valor nominal y que confieran los mismos derechos económicos, que no políticos ${ }^{19}$.

En las sociedades laborales no es válida la creación de acciones o participaciones privadas del derecho de voto (art. 5.1 in fine LSLP), y la memoria anual de las sociedades laborales recogerá las variaciones de capital social que haya experimentado dicha sociedad durante el ejercicio económico de referencia (art. 5.4 LSLP). Lo que supone un control indirecto de los requisitos de composición subjetiva de las sociedades laborales.

Las clases de acciones y participaciones y los cambios de condición de sus titulares (v.gr. trabajador con contrato indefinido que se jubila o que causa baja voluntaria o no como personal laboral, que pasaría a la clase general) pueden cambiar los porcentajes de participación que recoge la norma, siendo cuestiones que deben cumplirse y que pueden limitar la aplicación de algunas de las previsiones de la LSC en materia de ampliación de capital.

\section{Doble control de legalidad: Registro Mercantil y Registro Administrativo.}

Las ampliaciones de capital en una sociedad laboral se ven afectadas por el art. 4.4 LSLP que señala que el Registro Mercantil no practicará ninguna inscripción de modificación de estatutos de una sociedad laboral que afecte a su denominación, domicilio social, composición del capital social o régimen de transmisión de acciones y participaciones, sin que se aporte por la misma certificado del Registro de Sociedades Laborales del que resulte, o bien la resolución favorable de que

18 Las acciones o participaciones que sean propiedad de los trabajadores cuya relación laboral lo sea por tiempo indefinido se denominarán de «clase laboral» y las restantes «clase general» (art. 5.2. LSLP). En los supuestos de transmisión de acciones o participaciones que supongan un cambio de clase por razón de su propietario, los administradores sin necesidad de acuerdo de la Junta General procederán a formalizar la modificación del artículo o artículos de los estatutos a los que ello afecte, otorgando la pertinente escritura pública que se inscribirá en el Registro Mercantil, una vez inscrita en el Registro de Sociedades Laborales (Art. 5.3 LSLP).

19 Como señala, FAJARDO GARCÍA, G., "La sociedad laboral. Concepto, calificación, descalificación y principales características", en AA.VV. Participación de los trabajadores en la empresa y sociedades laborales", Tirant lo blanch, Valencia, 2018, pp. 589-630, p. 612; durante la tramitación parlamentaria se modificó el proyecto y se eliminó la referencia a que debieran tener todas las acciones y participaciones los mismos derechos de voto, justificándose dicha modificación en aras de liberalizar o facilitar el desarrollo de las sociedades laborales, si bien a su juicio, realmente parecen mayores los perjuicios que se pueden ocasionar que las mejoras. 
dicha modificación no afecta a la calificación de la sociedad como laboral, o bien la anotación registral del cambio de domicilio.

Los Registradores Mercantiles remitirán al registro administrativo correspondiente, preferentemente en formato electrónico la modificación de los actos relacionados en el párrafo anterior (art. 4.5 LSLP).

Además, el juez que conozca de la impugnación de algún acuerdo social que afecte a la denominación, composición del capital o al cambio de domicilio, pondrá en conocimiento del registro administrativo del que dependa la sociedad la existencia de la demanda y las causas de impugnación, así como la sentencia que dicte sobre la demanda (art. 4.7 LSLP).

En definitiva, las obligaciones de comunicación de los Registros, o en su caso Juzgados competentes, respecto a la inscripción de una ampliación de capital de una sociedad laboral, permite un mayor control de los límites de participación que se imponen a las mismas.

\section{LAS NORMAS SUSTANTIVAS EN MATERIA DE AMPLIACIÓN DE CAPITAL APLICABLES A LAS SOCIEDADES LABORALES PREVISTAS EN SU LEY REGULADORA O EN LA LEY DE SOCIEDADES DE CAPITAL}

Abordar un análisis de los requisitos legales para formalizar una ampliación de capital en una sociedad laboral no se puede hacer de forma estanca, revisando primero las normas especiales de la LSLP, y acto seguido las normas de la LSC que no deban entenderse excluidas por dicha regulación especial. Para conocer el régimen jurídico resultante de ambas normativas hemos de analizar la ampliación de capital en las sociedades laborales en su conjunto, especificando aquellas materias que sean propias de las sociedades laborales y que por tanto excluyen la aplicación de las reglas generales de la LSC.

\section{1. Órgano competente, propuesta de ampliación y convocatoria}

En el procedimiento a seguir para la aprobación de una ampliación de capital social, hemos de partir de las normas previstas en la LSC al no existir previsión específica, en dicha cuestión, en la LSLP.

En cuanto al órgano competente, el acuerdo de ampliación de capital de una sociedad laboral habrá de acordarse por la junta general con los requisitos establecidos para la modificación de los estatutos sociales (art. 296.1 LSC), sin perjuicio de la posibilidad, en las sociedades anónimas laborales, de delegación en el órga- 
no de administración respecto a la implementación de una ampliación de capital (art. $297 \mathrm{LSC})^{20}$.

La ampliación de capital, como toda modificación de estatutos, exige que exista una propuesta relativa a la modificación al alza de la cifra de capital social, bien de los administradores o, en su caso, de todos o parte de los socios. Unos u otros, deberán redactar el texto íntegro de la ampliación de capital que proponen y, en las sociedades anónimas laborales, deberán elaborar, además, un informe escrito con la justificación del aumento del capital social ${ }^{21}$.

La convocatoria de la junta general que haya de resolver sobre la ampliación de capital corresponde al órgano de administración en la forma y plazos previstos en los estatutos y en su defecto en la Ley de Sociedades de Capital ${ }^{22}$.

Es aplicable a las sociedades laborales, lo dispuesto en el art. 287 LSC para las convocatorias de junta general en la que se proponga una modificación de estatutos de las sociedades de capital, de forma que en el anuncio de convocatoria de la junta, deberán expresarse con la debida claridad los extremos que hayan de modificarse y hacer constar el derecho que corresponde a todos los socios de examinar en el domicilio social el texto íntegro de la modificación propuesta y, en el caso de sociedades anónimas, del informe sobre la misma, así como pedir la entrega o el envío gratuito de dichos documentos.

En definitiva, el orden del día deberá ser lo suficientemente claro para que los accionistas o socios puedan conocer la operación de ampliación planteada (importe, aportaciones, etc.) sin perjuicio de poder ejercer su derecho de información en aquello que no quede reflejado en la convocatoria (v.gr. respeto o exclusión del derecho de suscripción o asunción preferente, según el caso).

20 Vid. ALCALÁ DÍAZ, M.A., "La delegación en el consejo de administración del aumento de capital", en AA.VV. Sociedades cotizadas y transparencia en los mercados, Aranzadi, Cizur Menor, 2019 , pp. 25-64, que analiza en profundidad los requisitos para que la junta general delegue en los administradores, bien la facultad de señalar la fecha en que el acuerdo ya adoptado de aumentar el capital social deba llevarse a efecto en las condiciones fijadas, bien la a facultad de acordar en una o varias veces el aumento del capital social hasta una cifra determinada en la oportunidad y en la cuantía que ellos decidan, sin previa consulta a la junta general.

${ }^{21}$ ALONSO LEDESMA, C. "La modificación de los estatutos sociales. Aumento y reducción de capital", RdS, núm. 36, 2011-1, pp 1-15, p. 4, no considera oportuno que se "siga manteniendo solamente para las sociedades anónimas, la necesidad de redactar un informe justificativo de la modificación y el derecho que asiste a los socios de solicitar la entrega o el envío gratuito de dichos documentos en lugar de extenderlo también a la SRL como propugnaban algunos autores, citando a EMBID IRUJO, J.M.

22 No reiteramos aquí el régimen de la convocatoria y sus especialidades (v.gr. solicitud por la minoría, complemento de la convocatoria en las SAL, posibilidad de junta universal, etc.). Vid., por todos, CABANAS TREJO, R., "Convocatoria y celebración de la junta genera. Junta Universal, Acta Notarial”, Cuadernos de Derecho y Comercio, núm. 68, 2017, pp. 163-218. 


\section{Quorums y mayorías para aprobar un aumento de capital}

Sí que existen normas especiales para las sociedades laborales en relación a las mayorías necesarias para la adopción de acuerdos de ampliación de capital.

Dada la trascendencia de cumplir con los porcentajes de participación de los socios analizados supra, cuando el aumento de capital tenga como objeto la acomodación del capital a los referidos límites, el correspondiente acuerdo de aumento podrá aprobarse por acuerdo de la Junta General, sin mayorías reforzadas, siendo suficiente la mayoría ordinaria establecida para las sociedades de responsabilidad limitada en el artículo 198 LSC ${ }^{23}$, y con el quórum de constitución y las mayorías establecidas para las sociedades anónimas en los artículos 193 (quorum ordinario $)^{24}$ y 201 de dicha ley ${ }^{25}$.

En el resto de ampliaciones de capital no destinadas a cumplir los porcentajes de participación son de aplicación los quórums y mayorías previstas en la LSC:

a) En las sociedades limitadas laborales el acuerdo de ampliación, como modificación de los estatutos sociales, se adoptará conforme a lo dispuesto en el art. 199 LSC sobre mayoría legal reforzada, exigiendo "el voto favorable de más de la mitad de los votos correspondientes a las participaciones en que se divida el capital social". No existe, formalmente, un quorum de asistentes, pero queda claro que, si no comparecen socios cuyo capital, personalmente o representado, exceda de la mitad del total capital social no se podrá adoptar ningún acuerdo de ampliación de capital ${ }^{26}$.

b) El régimen, para las sociedades anónimas laborales, exige el cumplimiento de lo dispuesto en los artículos 194 y 201 LSC, lo que significa que, sin perjuicio de que los estatutos sociales puedan elevar el quórum legalmente previsto, para que la junta general ordinaria o extraordinaria pueda acordar válidamente, entre otros, el acuerdo de aumento del capital, será necesaria, en primera convocatoria, la concurrencia de accionistas presentes o representados que posean, al menos, el cincuenta por ciento del capital suscrito

\footnotetext{
${ }^{23}$ En la SL, mayoría de los votos siempre que representen al menos un tercio de los votos correspondientes a las participaciones sociales en que se divida el capital social, sin computar los votos en blanco.

24 En las SA, si los estatutos no fijan un quórum distinto, la junta quedará constituida en primera convocatoria cuando los accionistas presentes o representados posean, al menos, el veinticinco por ciento del capital suscrito con derecho de voto y en segunda convocatoria cualquiera que sea el capital concurrente a la misma.

25 "En las SA, mayoría simple de los votos de los accionistas presentes o representados en la junta, entendiéndose adoptado un acuerdo cuando obtenga más votos a favor que en contra del capital presente o representado".

26 Todo lo expuesto, sin perjuicio de que para todos o algunos asuntos determinados, los estatutos podrán exigir un porcentaje de votos favorables superior al establecido por la ley, sin llegar a la unanimidad (art. 200 LSC).
} 
con derecho de voto. Y en segunda convocatoria será suficiente la concurrencia del veinticinco por ciento de dicho capital.

Para la adopción de los acuerdos de ampliación de capital, una vez alcanzado el quorum, si el capital presente o representado supera el cincuenta por ciento bastará con que el acuerdo se adopte por mayoría absoluta. Sin embargo, se requerirá el voto favorable de los dos tercios del capital presente o representado en la junta cuando en segunda convocatoria concurran accionistas que representen el veinticinco por ciento o más del capital suscrito con derecho de voto sin alcanzar el cincuenta por ciento. Los estatutos sociales podrán elevar las mayorías referidas ${ }^{27}$.

El acuerdo de modificación de estatutos, y por tanto el de ampliación de capital se hará constar en escritura pública que se inscribirá en el Registro Mercantil, y el registrador mercantil remitirá de oficio, de forma telemática y sin coste adicional alguno, el acuerdo inscrito para su publicación en el Boletín Oficial del Registro Mercantil (art. 290 LSC) ${ }^{28}$.

\section{Modalidades del aumento del capital. Tipos de aportaciones}

Para las sociedades laborales su ley reguladora no contiene ninguna especialidad respecto a las modalidades de la ampliación de capital y, por tanto, esta podrá realizarse por creación de nuevas participaciones o emisión de nuevas acciones, o por elevación del valor nominal de las ya existentes (art. 295 LSC).

De este modo, cuando el aumento haya de realizarse elevando el valor nominal de las participaciones o de las acciones será preciso el consentimiento de todos los socios, salvo que se haga íntegramente con cargo a beneficios o reservas que ya figurasen en el último balance aprobado (art. 296.2 LSC).

En las sociedades anónimas laborales, el valor nominal de cada una de las acciones de la sociedad, una vez aumentado el capital, lógicamente, habrá de estar desembolsado en una cuarta parte como mínimo (art. 296.3 LSC).

En ambos casos el aumento del capital podrá realizarse con cargo a nuevas aportaciones dinerarias o no dinerarias al patrimonio social, incluida la aportación de créditos contra la sociedad, o con cargo a beneficios o reservas que ya figurasen en el último balance aprobado ${ }^{29}$.

27 Vid. SAINZ MUÑOZ, G., Normas generales sobre votación de acuerdos en sociedades anónimas; adopción separada de acuerdos y régimen de mayorías, en AA.VV., Comentario práctico a la nueva normativa de Gobierno Corporativo. Ley 31/2014, de reforma de la Ley de Sociedades de Capital, Dir. RECALDE CASTELLS y ARIAS VARONA, F.J., Dikynson, 2016, pp. 51-56.

${ }^{28}$ Vid. supra las obligaciones de comunicación entre el Registro Mercantil y el Registro Administrativo de sociedades laborales cuando se pretenda la inscripción de un acuerdo de ampliación, en cuanto modifica la composición del capital social.

${ }^{29}$ Como señalan, IGLESIAS PRADA, J.L., y GARCÍA DE ENTERRÍA, J., "Lección 24. La modificación de los estatutos sociales. Aumento y Reducción de capital. Separación y exclusión de socios", 
En principio, se podrán crear acciones o participaciones con y sin prima de emisión o de asunción, si bien como se referirá infra, en las ampliaciones de capital en las que se quiera excluir el derecho de preferencia, y la exclusión afecte a las acciones o participaciones de la clase laboral, la LSLP (art. 11.4) establece que la prima será fijada libremente por la Junta General, siempre que la misma apruebe un Plan de adquisición de acciones o participaciones por los trabajadores de la sociedad con contrato por tiempo indefinido, y que las nuevas acciones o participaciones se destinen al cumplimiento de dicho Plan e imponga la prohibición de enajenación en un plazo de cinco años. No existiendo en la LSLP ninguna otra referencia a la prima de emisión, para cualquier otra cuestión distinta de la referida serán de aplicación las normas de la $\mathrm{LSC}^{30}$.

Igualmente serán de aplicación a las sociedades laborales las normas relativas a los requisitos de las aportaciones dinerarias y no dinerarias. Respecto a las primeras, las sociedades limitadas han quedado exoneradas de aportar la certificación bancaria acreditativa del desembolso en la constitución, pero no así en la ampliación de capital $^{31}$, donde seguirá siendo necesaria la acreditación bancaria del desembolso, como en las sociedades anónimas; que además para todo aumento del capital cuyo contravalor consista en nuevas aportaciones dinerarias al patrimonio social, exigen como requisito previo, salvo para las entidades aseguradoras (actividad no asumible por una sociedad laboral), el total desembolso de las acciones anteriormente emitidas. Si bien, podrá realizarse el aumento si existe una cantidad pendiente de desembolso que no exceda del tres por ciento del capital social.

Respecto a las aportaciones no dinerarias, es de aplicación el régimen general por todos conocido, que se resume en la valoración por experto independiente

en AA.VV. Lecciones de Derecho Mercantil, Volumen I, Dirs. MENÉNDEZ, A. Y ROJO, A., Civitas, Cizur Menor, 2013, pp. 541-564, pp. 546 y 547, es importante aclarar que no siempre la ampliación de capital comporta un correlativo aumento del patrimonio de la sociedad, al ser posible que los fondos o aportaciones con que se desembolsa el nuevo capital, el contravalor del aumento, estén integrados en el patrimonio social con anterioridad a la operación (casos de ampliación con cargo a reservas o mediante compensación de créditos).

30 TRÍAS SAGNIER, M., "El precio de las acciones en las ampliaciones de capital. Comentarios a la Sentencia de la Sección 15 de la Audiencia Provincial de Barcelona de fecha 4 de junio de 2004 y reflexiones críticas en torno a la línea jurisprudencial del Tribunal Supremo en la materia”, RdS, núm. 25,2005 , pp. 1-19, p. 10, es contrario a que se afirme que existe "un derecho de los órganos sociales de establecer con total libertad el precio de las nuevas acciones a emitir en una ampliación de capital, sin más limitaciones que las reglas que obligan a no emitir por debajo de la par en las ampliaciones de capital con reconocimiento del derecho de suscripción preferente, porque ello deja a los accionistas en una situación de desprotección. Esta deficiencia tutelar puede desembocar en transferencias de valor a favor de los accionistas que suscriben la ampliación, atribuyéndoles un enriquecimiento injusto".

31 Ley 11/2018, de 28 de diciembre, por la que se modifica el Código de Comercio, el texto refundido de la Ley de Sociedades de Capital aprobado por el Real Decreto Legislativo 1/2010, de 2 de julio, y la Ley 22/2015, de 20 de julio, de Auditoría de Cuentas, en materia de información no financiera y diversidad. 
designado por el Registro Mercantil, obligatoria en las sociedades anónimas laborales y voluntaria en las sociedades limitadas laborales, si se quiere evitar el régimen de responsabilidad legalmente previsto ${ }^{32}$.

Respecto al aumento por compensación de créditos, lo dispuesto en las LSC es aplicable a las sociedades laborales, cumpliendo los requisitos legalmente previstos $^{33}$, si bien al exigir la LSLP que deberá respetarse la proporción existente entre las acciones o participaciones pertenecientes a las dos clases con que cuente la sociedad (art. 11 LSLP), ello obligará a que si algunos de los accionistas o socios no ostentan créditos compensables con los que ejercitar su derecho de suscripción preferente los administradores deberán prever un tramo de aportaciones dinerarias, reservado para dichos socios, que les permita obtener un número de acciones que les otorgue un porcentaje en el capital social equivalente al que hubieran obtenido en caso de ejercicio de su derecho de suscripción preferente (cuestión irrealizable si todos los créditos a compensar son de terceros no socios o si no hay consenso entre todos los socios para el reparto de las acciones o participaciones nuevas) ${ }^{34}$.

32 Las personas que ostentaran la condición de socio en el momento de acordarse el aumento de capital y quienes adquieran alguna participación desembolsada mediante aportaciones no dinerarias, responderán solidariamente frente a la sociedad y frente a los acreedores sociales de la realidad de dichas aportaciones y del valor que se les haya atribuido en la escritura (art. 73.1 LSC). Si bien, si la aportación se hubiera efectuado como contravalor de un aumento del capital social, quedarán exentos de esta responsabilidad los socios que hiciesen constar en acta su oposición al acuerdo o a la valoración atribuida a la aportación (art. 73.2 LSC). En caso de aumento del capital social con cargo a aportaciones no dinerarias, además de las personas referidas, también responderán solidariamente los administradores por la diferencia entre la valoración que hubiesen realizado y el valor real de las aportaciones (art. 73.3 LSC).

${ }^{33}$ Cuando el aumento del capital de la SL se realice por compensación de créditos, éstos habrán de ser totalmente líquidos y exigibles. Cuando el aumento del capital de la anónima se realice por compensación de créditos, al menos, un veinticinco por ciento de los créditos a compensar deberán ser líquidos, estar vencidos y ser exigibles, y el vencimiento de los restantes no podrá ser superior a cinco años. Más el informe de administradores en ambos casos, el certificado del auditor en las SAL, y las menciones obligatorias en la convocatoria.

34 PULGAR ESQUERRA, J., "El acuerdo de la junta de aumento de capital por compensación de créditos en el marco de las sociedades de capital", RdS, núm. 34, 2010, pp. 1-38, p. 26, analiza tanto la doctrina a favor como en contra de la existencia ex lege de una exclusión del derecho de suscripción preferente en las ampliaciones de capital por compensación de créditos. Para, ALONSO LEDESMA, C, "La modificación de los estatutos sociales...", est. cit., p. 10, con el TRLSC consideraba que "definitivamente, tanto en la sociedad anónima como en la sociedad limitada el derecho de preferencia de los antiguos socios no llegará a nacer porque sólo se reconoce en los casos de aumento de capital con aportaciones dinerarias con lo que la junta deja de poder apreciar si, efectivamente, es o no necesario para la sociedad esa conversión de créditos contra la sociedad en acciones o participaciones, o si se requieren realmente esas aportaciones no dinerarias y, si así fuera, proceder a la exclusión del derecho de preferencia". Con ello, concluye, que evidentemente, puede lesionarse con más facilidad el derecho de los antiguos accionistas a mantener su nivel relativo de participación en la sociedad, fundamentalmente en las sociedades cerradas como la SL en que esta modalidad de aumento sin reconocer el 
También serán aplicables a las sociedades laborales las reglas del aumento con cargo a reservas previstas en el art. 303 LSC, para lo que podrán utilizarse para tal fin las reservas disponibles, las reservas por prima de asunción de participaciones sociales o de emisión de acciones y la reserva legal en su totalidad, si la sociedad fuera de responsabilidad limitada, o en la parte que exceda del diez por ciento del capital ya aumentado, si la sociedad fuera anónima ${ }^{35}$. Hemos de recordar, que el aumento de capital con cargo a reservas o beneficios se puede realizar sin el consentimiento de todos los socios cuando el aumento se realice elevando el valor nominal de las participaciones o de las acciones (art. 296.2 LSC). Han surgido críticas a la extensión que se ha hecho a la SL de la obligación de que el balance que sirve de base a la operación tenga que ser verificado por un auditor nombrado por el Registro Mercantil a solicitud de los administradores (art. 303), y ello porque eso supone un incremento de gastos para las sociedades pequeñas que no resulta especialmente justificado desde ningún punto de vista ${ }^{36}$, cuestión que afecta a las sociedades laborales en cuanto en su mayoría son pequeñas o medianas empresas.

No hacemos referencia a la regulación de la oferta pública de suscripción de acciones en cuanto las normas del mercado de valores no son de aplicación a las sociedades laborales.

derecho de asunción preferente puede utilizarse para diluir muy significativamente al minoritario. Por nuestra parte, proponemos que en los supuestos de que solo algunos socios ostenten créditos frente a la sociedad, aprobar dos tramos de ampliación de capital, el segundo de ellos de carácter dinerario para respetar el derecho de suscripción preferente. Si los créditos son de terceros el debate referido, entre considerar o no excluido ex lege el derecho de suscripción preferente, sigue abierto.

35 A la operación deberá servir de base un balance aprobado por la junta general referido a una fecha comprendida dentro de los seis meses inmediatamente anteriores al acuerdo de aumento del capital, verificado por el auditor de cuentas de la sociedad, o por un auditor nombrado por el Registro Mercantil a solicitud de los administradores, si la sociedad no estuviera obligada a verificación contable.

${ }^{36}$ Así lo indica ALONSO LEDESMA, C., "La modificación de los estatutos sociales...", est. cit., p. 7, añadiendo que si la eliminación, en su momento, de muchos de los requisitos exigidos para la SA tales como la valoración de las aportaciones no dinerarias por experto independiente, o la verificación de las cuentas por auditor se realizó para eliminar cargas y trabas para estas pequeñas sociedades y esa eliminación fue compensada por la implantación de un sistema de responsabilidad más riguroso para socios o administradores (que se mantiene), no se entiende cuál es la razón por la que ahora se exige esta verificación. Y menos se entiende si se repara en que tal exigencia no se prevé para el aumento por compensación de créditos, supuesto en el que se pide para la SA la verificación de la contabilidad social para comprobar que, efectivamente resultan exactos los datos ofrecidos por los administradores sobre los créditos a compensar. La identidad de razón en ambos casos hubiera exigido mantener el mismo régimen que, desde luego, debería ser el existente en la derogada LSRL, y no establecer esta diferencia de tratamiento en dos supuestos semejantes que de ninguna forma está justificada. 


\section{Aumento incompleto}

Respecto a las Sociedades Laborales, Anónimas o Limitadas, la LSC mantiene los criterios de las normas refundidas (LSA y LSRL), por lo que para las SLL son de aplicación las reglas previstas en el art. 310 LSC, que establece para este tipo social que cuando el aumento del capital social no se haya desembolsado íntegramente dentro del plazo fijado al efecto, el capital quedará aumentado en la cuantía desembolsada, salvo que en el acuerdo se hubiera previsto que el aumento quedaría sin efecto en caso de desembolso incompleto ${ }^{37}$.

En sentido contrario, para las Sociedades Anónimas Laborales, es de aplicación el art. 311 LSC, que establece que, en las SA, cuando el aumento del capital no se haya suscrito íntegramente dentro del plazo fijado para la suscripción, el capital sólo se aumentará en la cuantía de las suscripciones efectuadas si las condiciones de la emisión hubieran previsto expresamente esta posibilidad ${ }^{38}$.

\section{Ejecución de la ampliación de capital}

Respecto a la suscripción y desembolso del importe de la ampliación son de aplicación a las sociedades laborales, por un lado, el art. 312 LSC que señala que quienes hayan asumido las nuevas participaciones o suscrito las nuevas acciones quedan obligados a hacer su aportación desde el momento mismo de la suscripción, si bien con los matices de los arts. 78 y 79 LSC respecto a la cantidad a desembolsar de las participaciones asumidas, será siempre del cien por cien del valor nominal (y de la prima de asunción, en su caso) en las sociedades laborales de responsabilidad limitada, y en las sociedades anónimas laborales, las acciones en que se divida el capital deberán estar íntegramente suscritas por los socios, y desembolsado, al menos, en una cuarta parte el valor nominal de cada una de ellas en el momento de ejecutar el aumento del capital social y la totalidad de la prima de emisión de cada una de ellas

37 En las SLL, en caso de que el aumento del capital quede sin efecto, el órgano de administración, dentro del mes siguiente al vencimiento del plazo fijado para el desembolso, deberá restituir las aportaciones realizadas. Si las aportaciones fueran dinerarias, la restitución podrá hacerse mediante consignación del importe a nombre de los respectivos aportantes en una entidad de crédito del domicilio social, comunicando a éstos por escrito la fecha de la consignación y la entidad depositaria. Para las SAL será de aplicación, en el caso de que el aumento del capital quede sin efecto, que el órgano de administración lo publicará en el Boletín Oficial del Registro mercantil y, dentro del mes siguiente al vencimiento del plazo de suscripción, deberá restituir las aportaciones realizadas. Si las aportaciones fueran dinerarias, la restitución deberá hacerse directamente a los respectivos aportantes o mediante consignación del importe a nombre de éstos en el Banco de España o en la Caja General de Depósitos.

38 Sobre la suscripción incompleta del aumento de capital y su distinta regulación para las SA y las SL, vid. FLAQUER RITUORT, J. "Breves notas sobre la suscripción incompleta del aumento de capital”, Diario La Ley, núm. 8611, 23 de septiembre de 2015, pp. 1-9. 
En cuanto a la inscripción de la ampliación de capital, junto a las menciones exigidas por el Registro Administrativo, son de aplicación a las sociedades laborales las siguientes reglas contenidas en sede de LSC, al regular la inscripción de la operación de aumento. En tal sentido, una vez ejecutado el acuerdo de aumento del capital social, los administradores deberán dar nueva redacción a los estatutos sociales a fin de recoger en los mismos la nueva cifra de capital social, a cuyo efecto se entenderán facultados por el acuerdo de aumento (art. 313 LSC).

La escritura que documente la ejecución deberá expresar los bienes o derechos aportados y, en el caso de las sociedades de responsabilidad limitada o de las anónimas no cotizadas, si el aumento se hubiera realizado por creación de nuevas participaciones sociales o por emisión de nuevas acciones, la identidad de las personas a quienes se hayan adjudicado, la numeración de las participaciones o de las acciones atribuidas, así como la declaración del órgano de administración de que la titularidad de las participaciones se ha hecho constar en el Libro-registro de socios o de que la titularidad de las acciones nominativas se ha hecho constar en el Libro-registro de acciones nominativas (art. 314 LSC). En las sociedades laborales, deberá constar la clase de cada una de las acciones emitidas, laboral o general, al objeto de la comprobación del cumplimiento de los límites de porcentajes de los socios laborales.

El acuerdo de aumento del capital social y la ejecución del mismo deberán inscribirse simultáneamente en el Registro Mercantil (art. 315.1 LSC) ${ }^{39}$.

También es aplicable a las sociedades laborales el régimen previsto en la LSC respecto al derecho a la restitución de aportaciones, en los supuestos en que hubieran transcurrido seis meses desde la apertura del plazo para el ejercicio de derecho de preferencia sin que se hubieran presentado para su inscripción en el Registro los documentos acreditativos de la ejecución del aumento del capital. En

39 Para, VICENT CHULIÁ, F., 9. ${ }^{a}$ Modificación de estatutos, modificaciones estructurales, salida de socios, disolución y liquidación de las sociedades de capital, en AA.VV. Introducción al Derecho Mercantil, Dir. VICENT CHULIÁ, F., Tirant lo blach, Valencia, 2012, Versión electrónica, TOL2.727.030, pp. 1-114, p. 4; la inscripción de las modificaciones estatutarias en el Registro Mercantil, en general, no es constitutiva, es decir, no es requisito para la eficacia de la modificación de estatutos, que produce efectos desde la adopción del acuerdo social (ver STS 17 junio 1994, R. 4.930, "Hormigones Vascos, S.A.”: modificación estatutaria reforzando la mayoría para adoptar acuerdos). Por su parte, la publicación en el BORME produce efectos de oponibilidad a terceros. Ver arts. 144 y ss. LSA. Pero, a pesar de ser una cuestión de gran importancia práctica, ni la legislación ni la doctrina han dado una solución pacífica sobre el momento en que se produce la eficacia plena del aumento y reducción del capital social, pero para este autor, según la interpretación que considera acorde con el Derecho positivo, el nacimiento de las nuevas participaciones y acciones en el aumento del capital y su extinción en el caso de reducción sólo se produce con la inscripción registral. Antes de ella, en el caso de aumento, el suscriptor de participaciones y acciones correspondientes al aumento de capital sólo tiene los derechos de suscriptor, que, como derechos patrimoniales que son, puede transmitir, a pesar del art. 34 LSC (que es refundición de los arts. 62 LSA y 28 LSL); y, en el caso de reducción, sigue siendo socio. 
dicho caso, quienes hubieran asumido las nuevas participaciones sociales o los suscriptores de las nuevas acciones podrán pedir la resolución de la obligación de aportar y exigir la restitución de las aportaciones realizadas (art. 316 LSC) $)^{40}$.

\section{ESPECIAL REFERENCIA A LOS DERECHOS DE SUSCRIPCIÓN Y ASUNCIÓN PREFERENTE EN LAS SOCIEDADES LABORALES}

La ejecución de una ampliación de capital puede suponer la dilución de la participación de los socios que no suscriban o asuman las nuevas acciones o participaciones, si bien el derecho de suscripción o asunción preferente de los socios permite conciliar la necesidad de la sociedad de obtener nuevos recursos y la de respetar la posición jurídica del socio en la entidad ${ }^{41}$.

El art. 11 LSLP regula el derecho de suscripción o asunción preferente para las sociedades laborales, estableciendo que en toda ampliación de capital con emisión de nuevas acciones o con creación de nuevas participaciones sociales, omitiendo la referencia expresa prevista en la LSC que exige, para que exista derecho de suscripción o asunción preferente, que las ampliaciones lo han de ser con cargo a aportaciones dinerarias, lo que tiene cierto sentido cuando se trata de no perjudicar la realización de aportaciones no dinerarias beneficiosas para la sociedad ${ }^{42}$. Y aunque es una cuestión relevante que no se perjudique el porcentaje del tramo de clase laboral (proporción para no perder su condición de sociedad laboral), podría preverse una ampliación de capital con dos tramos, dinerario y no dinerario, para que todos los socios puedan tener la misma proporción en el capital resultante.

El objetivo del derecho de suscripción y asunción preferente en ambos textos legales tiene por objeto respetar la proporción de acciones y participaciones existente entre los socios, si bien en la sociedad laboral dicha proporción lo es, en especial, entre las acciones y participaciones pertenecientes a las dos clases con que puede contar la sociedad ${ }^{43}$, excepto cuando el aumento de capital tenga como

40 Si la falta de presentación de los documentos a inscripción fuere imputable a la sociedad, podrán exigir también el interés legal.

${ }^{41}$ LARA, R. "Sección 3a. La ejecución del acuerdo de aumento. Art. 304 Derecho de preferencia", en AA.VV, Comentario de la Ley de Sociedades de Capital, Tomo II, Dir. ROJO, A. y BELTRÁN, E., Civitas, Navarra, 2011, p. 2.248, que refiere asimismo la SAP de Asturias de 29 de octubre de 1999.

${ }^{42}$ En la LSC dicha inexistencia del derecho de suscripción preferente respecto de las aportaciones no dinerarias se ha venido entendiendo como una imposibilidad del resto de socios no aportantes de poder sustituir los bienes aportados en especie (GARCÍA GREWE, C., El derecho de suscripción preferente. Exclusión, inexistencia y configuración estatutaria, Civitas, Navarra, 2014, pp. 385-367).

43 Los titulares de acciones o de participaciones pertenecientes a cada una de las clases, tienen derechos de preferencia para suscribir o asumir las nuevas acciones o participaciones sociales pertenecientes a la clase respectiva (art. 11.2 LSLP). Como destaca, VAÑÓ VAÑÓ, M.J., "Modificación 
objeto la acomodación del capital a los límites a que se refiere el artículo 1, 2.a) y b) de esta ley ${ }^{44}$.

En materia de los plazos a seguir por la sociedad laboral en el ejercicio del derecho de suscripción o asunción preferente, nos hemos de remitir de forma subsidiaria a lo establecido en el régimen general del art. $305 \mathrm{LSC}^{45}$. La misma remisión se ha de realizar en materia de transmisión de los derechos de suscripción y asunción preferente cuestión en la que resultan de aplicación los derechos estatutarios y en su defecto legales de adquisición preferente, tendentes a la protección de los tramos de las clases laboral y general ${ }^{46}$.

Respecto a la necesidad o voluntariedad de ofrecer las acciones emitidas o participaciones creadas en una segunda vuelta, en la LSC, para las sociedades anónimas, es voluntaria su inclusión en las condiciones del acuerdo de ampliación de capital ${ }^{47}$, y como la LSLP señala, que si no se consigna en el acuerdo de

de capital y derecho de preferencia en las sociedades laborales", en AA.VV. Participación de los trabajadores en la empresa y sociedades laborales", Tirant lo blanch, Valencia, 2018, pp. 755-772, p. 768 , "el derecho de preferencia de los socios en el aumento de capital ha sido objeto de una profunda simplificación respecto al régimen jurídico anterior, lo que conlleva una reducción de plazos y del colectivo con derechos de preferencia, suprimiendo el derecho que ostentaban los trabajadores de duración determinada".

44 En estos casos, el aumento de capital, como referimos supra podrá adoptarse por acuerdo de la Junta General con la mayoría ordinaria para las SL y con el quórum de constitución y las mayorías establecidas para las SA en los artículos 193 y 201 de dicha ley.

45 En las SL, el derecho de preferencia se ejercitará en el plazo que se hubiera fijado al adoptar el acuerdo de aumento. En las SA, el derecho de preferencia se ejercitará en el plazo que determinan los administradores. El plazo para el ejercicio del derecho no podrá ser inferior a un mes desde la publicación del anuncio de la oferta de asunción de las nuevas participaciones o de suscripción de nuevas acciones en el Boletín Oficial del Registro Mercantil. En las SL y en las SA cuando todas las acciones sean nominativas, el órgano de administración podrá sustituir la publicación del anuncio por una comunicación escrita a cada uno de los socios y, en su caso, a los usufructuarios inscritos en el Libro registro de socios o en Libro de acciones nominativas, computándose el plazo de asunción de las nuevas participaciones o de las nuevas acciones desde el envío de la comunicación.

${ }^{46}$ En todo caso, en las SL, la transmisión voluntaria por actos «inter vivos» del derecho de asunción preferente de las nuevas participaciones sociales podrá efectuarse a favor de las personas que, conforme a esta ley o a los estatutos de la sociedad puedan adquirir libremente las participaciones sociales. Los estatutos podrán reconocer, además, la posibilidad de la transmisión de este derecho a otras personas, sometiéndola al mismo sistema y condiciones previstos para la transmisión «inter vivos» de las participaciones sociales, con modificación, en su caso, de los plazos establecidos en dicho sistema. En las SA los derechos de suscripción preferente serán transmisibles en las mismas condiciones que las acciones de las que deriven.

47 Si bien, en las sociedades de responsabilidad limitada, salvo que los estatutos dispongan otra cosa, las participaciones no asumidas en el ejercicio del derecho de preferencia serán ofrecidas por el órgano de administración a los socios que lo hubieren ejercitado, para su asunción y desembolso durante un plazo no superior a quince días desde la conclusión del establecido para la asunción preferente. Si existieren varios socios interesados en asumir las participaciones ofrecidas, éstas se adjudicarán en proporción a las que cada uno de ellos ya tuviere en la sociedad (art. 307.1 LSC). 
ampliación esa segunda vuelta, ello puede tener implicaciones para los socios trabajadores, ya que salvo acuerdo de la Junta General que adopte el aumento del capital social, las acciones o participaciones no suscritas o asumidas por los socios de la clase respectiva se ofrecerán a los trabajadores con contrato por tiempo indefinido, en la forma prevista en el artículo $6^{48}$. No a favor de los socios que hubieren suscrito sino de los trabajadores con dichos requisitos, con lo que se consigue, así como objetivo el permitir el acceso de los trabajadores con contrato indefinido a la condición de socio.

La LSLP no recoge, como la LSC, que no habrá lugar al derecho de preferencia cuando el aumento del capital se deba a la absorción de otra sociedad o de todo o parte del patrimonio escindido de otra sociedad o a la conversión de obligaciones en acciones (art. 304.2 LSC). Ello no impide, por su aplicación subsidiaria, que se aplique a las sociedades laborales, si bien en el proyecto de fusión o escisión deberá contemplarse el resultado del reparto de las acciones de las dos clases, en particular para que los de la clase laboral sean los mayoritarios, además de que ningún socio tenga más de un tercio en el capital social.

La exclusión del derecho de preferencia, para los casos en los que el interés de la sociedad así lo exija, se regirá por la LSC (art. 308 LSC) ${ }^{49}$, salvo en los supuestos de operaciones acordeón (art. 343 LSC) en las que siempre deberá respetarse

48 Podrán transmitirse libremente las acciones y participaciones a los socios trabajadores y trabajadores no socios con contrato por tiempo indefinido" (art. 6.1 LSLP), y en el resto de transmisiones (no libres), se establece en el art. 6.2 LSLP que deben priorizarse los interesados, en caso de concurrencia, de acuerdo al siguiente orden de preferencia: (1) Trabajadores indefinidos no socios, en relación directa a su antigüedad en la empresa; (2) Socios trabajadores, en relación inversa al número de acciones o participaciones que posean; (3) Socios de la clase general, a prorrata de su participación en el capital social, (4) La sociedad.

49 Para excluir el derecho de preferencia se exigen determinados requisitos tendentes a asegurar que el valor de emisión (incluida en su caso la prima) permita a los socios "prexistentes" mantener sino el mismo porcentaje en el capital que tenían antes de la ampliación si el mismo valor patrimonial de su participación en el capital social tras la misma. En tal sentido VAZQUEZ ALBERT, D., "Art. 159 Exclusión del derecho de suscripción preferente", en AA.VV. Comentarios a la Ley de Sociedades Anónimas, Coord. ARROYO, I. y EMBID, J.M, Tecnos, Madrid, 2009, p. 1.666, que señala que la exclusión del derecho de preferencia causaría al accionista individual una dilución de su participación en el plano político, pero la prima de emisión le permitiría mantener su indemnidad patrimonial. Los requisitos para la exclusión del derecho de suscripción preferente son los previstos en el art. 308 LSC, que podemos resumir en (i) que los administradores elaboren un informe con el valor de las participaciones o de las acciones de la sociedad y la propuesta y la contraprestación a satisfacer por las nuevas participaciones o acciones, con la indicación de las personas a las que hayan de atribuirse, y, en las SA, que un experto independiente, nombrado a estos efectos por el R.M., elabore otro informe, bajo su responsabilidad, sobre la razonabilidad de los valores y los datos contenidos; (ii) que en la convocatoria de la junta se hayan hecho constar la propuesta de supresión del derecho de preferencia, el tipo de creación de las nuevas participaciones sociales o de emisión de las nuevas acciones y el derecho de los socios a examinar en el domicilio social el informe o los informes antes referidos así como pedir la entrega o el envío gratuito de estos documentos, y (iii) que el valor nominal de las nuevas participaciones o de las nuevas acciones, más, en su caso, el importe de la prima, se corresponda con 
el derecho de preferencia ${ }^{50}$. En particular, en las sociedades laborales cuando la exclusión del derecho de preferencia afecte a las acciones o participaciones de la clase laboral, la prima será fijada libremente por la Junta General, siempre que la misma apruebe un Plan de adquisición de acciones o participaciones por los trabajadores de la sociedad con contrato por tiempo indefinido, y que las nuevas acciones o participaciones se destinen al cumplimiento del Plan e imponga la prohibición de enajenación de las acciones o participaciones adquiridas en un plazo de cinco años, previsión que recoge expresamente el art. 8.2 LSLP, al que haremos referencia infra. Nuevamente, la especialidad de la LSLP en esta materia trata de promover el acceso de los trabajadores con contrato indefinido al capital social ${ }^{51}$.

\section{OTRAS CUESTIONES EN MATERIA DE AMPLIACIÓN DE CAPITAL}

\section{Prohibición de transmisión de acciones o participaciones objeto de ampliación}

El art. 8.1 LSLP declara válidas las cláusulas estatutarias que prohíban la transmisión voluntaria de las acciones o participaciones sociales por actos «inter vivos» si los estatutos reconocen al socio el derecho a separarse de la sociedad en cualquier momento. En consecuencia, en una ampliación de capital en las sociedades laborales, podrá acordarse, por unanimidad ${ }^{52}$, la referida prohibición de transmisión y el consecuente derecho de separación.

El derecho de separación confiere en la LSC al socio separado el derecho al reembolso del valor razonable de sus acciones o participaciones, si bien la LSLP no hace referencia explícita a dicha "razonabilidad". La única mención figura en el art. 16.4 LSLP que señala que el socio separado (o excluido) tendrá derecho a obtener en el domicilio social el valor de sus acciones o participaciones, tras-

\footnotetext{
el valor real atribuido a las participaciones en el informe de los administradores en el caso de las SL o con el valor que resulte del informe del experto independiente en el caso de las SA.

${ }^{50}$ Con ello se tratan de evitar las finalidades abusivas (ESPÍN, C., Art. 343 Reducción y aumento de capital simultáneos, Comentario de la ley de Sociedades de Capital, Tomo II, Dir. ROJO, A. y BELTRÁN, E., Civitas, Navarra, 2011, pp. 2.455-2.463, p. 2.455 que cita la STS de 9 de noviembre de 2007), en las que el grupo de control se desprenda de una minoría molesta o sencillamente mal avenida.

51 A nuestro entender, se exige un importante nivel de asesoramiento a las sociedades laborales, en cuanto a la preparación del referido Plan de adquisición de acciones o participaciones por los trabajadores de la sociedad con contrato por tiempo indefinido. Dicho Plan, deberá establecer el juego de las preferencias o no, en su caso, para la adjudicación correspondiente, así como el precio de suscripción o asunción, aspecto respecto al que la Junta podrá debatir ante las distintos precios satisfechos por cada socio y el valor de las nuevas acciones o participaciones.

52 La incorporación de estas cláusulas a los estatutos sociales exigirá el consentimiento de todos los socios art. 8.1 in fine LSC.
} 
mitidas o amortizadas. Podría entenderse, bien que el legislador no ha querido constreñir a las sociedades laborales a la hora de reembolsar a un socio que se separa permitiendo indirectamente su configuración estatutaria o, bien, en sentido contrario, que es de aplicación el valor razonable previsto que si que se prevé en las transmisiones voluntarias inter vivos (art. 6 LSLP). Lo cierto es que la mera expresión del valor de las acciones o participaciones, puede dar lugar a distintas interpretaciones, que de lege ferenda deberían resolverse ${ }^{53}$.

También modifica la LSLP el computo del plazo para dicho reembolso. Con carácter general, el art. 356 LSC fija dicho plazo en dos meses, desde la recepción del informe de valoración. Mientras que en el referido art. 16.4 LSLP, se establece que el reembolso se debe realizar "en el plazo máximo de cuatro meses a partir de la recepción del escrito por el que el socio comunica que ejercita su derecho de separación (...)”. En este caso la diferencia al alza en el cómputo del plazo para el reembolso a los socios separados en las sociedades laborales podría traer causa de que las acciones o participaciones de los socios separados deberán ser ofrecidas a los trabajadores de la sociedad con contrato de trabajo por tiempo indefinido, conforme a lo previsto en el art. 6 LSLP, y sus correspondientes plazos. Las acciones o participaciones no adquiridas deberán ser amortizadas mediante reducción del capital social.

Con especial incidencia para las ampliaciones de capital hemos de tener en también en consideración que, además de la previsión del párrafo anterior, el art. 8.2 LSLP recoge que los estatutos podrán impedir la transmisión voluntaria de las acciones o participaciones por actos «inter vivos», o el ejercicio del derecho de separación, sin exigirse la unanimidad, durante un período de tiempo no superior a cinco años a contar, entre otros supuestos, para las acciones o participaciones procedentes de una ampliación de capital, desde el otorgamiento de la escritura pública de su ejecución.

\section{Otras referencias: asistencia financiera y reserva especial}

La ley incorpora, por primera vez, la posibilidad de que la sociedad laboral facilite asistencia financiera a los trabajadores para la adquisición de sus propias acciones o participaciones por los trabajadores de la sociedad con contrato por tiempo indefinido que no sean socios (art. 12.4 LSLP). A nuestro entender, no queda autorizada la financiación para suscribir una ampliación de capital, siendo

53 En la propia Exposición de Motivos de la LSLP se reconoce que los derechos de separación y exclusión no estaban regulados hasta dicha ley. COMESAÑA COSTAS, J., La separación del socio, en AA.VV Participación de los trabajadores en la empresa y sociedades laborales, Dir. FAJARDO GARCÍA,G., Tirant lo blanch, Valencia, 2018, pp. 931-956, p. 946-947, por el contrario, considera que no se contempla ninguna restricción de las peculiaridades tipológicas de la sociedad laboral, por lo que concluye que la regulación del derecho de separación en la SA y la SL es plenamente aplicable a las sociedades laborales para ambos tipos de socios. 
la literalidad del artículo que se autoriza la asistencia financiera para la adquisición y no para la suscripción.

Además de las reservas legales o estatutarias que procedan, las sociedades, anónimas y limitadas, laborales están obligadas a constituir una reserva especial que se dotará con el diez por ciento del beneficio líquido de cada ejercicio, hasta que alcance al menos una cifra superior al doble del capital social (art. 14.1 LSLP) $)^{54}$. Una vez cubierta la reserva especial, la sociedad laboral deberá recordar que su importe deberá incrementarse si se aprueba una ampliación de capital posteriormente.

\section{Vi CONSIDERACIONES FINALES}

Ha quedado acreditado que las ampliaciones de capital cumplen una importante función en las sociedades laborales, ya sea como formula para captar fondos para el ejercicio de sus actividades, ya sea para permitir la entrada como socios de la clase laboral a los trabajadores no socios con contrato indefinido. Prueba de ello es como el derecho de suscripción preferente no se limita a las ampliaciones con aportaciones dinerarias o que la junta general puede determinar libremente la prima si se aprueba un Plan de adquisición de acciones o participaciones por los referidos trabajadores.

En toda ampliación de capital será necesario analizar y prever el porcentaje de cada socio y de cada clase de acciones o participaciones, ya que la LSLP mantiene la distinción entre acciones y participaciones de la clase laboral y general, para cumplir los porcentajes previstos en la LSLP para seguir cumpliendo los requisitos mínimos para seguir siendo sociedad laboral, si no se regularizan los excesos en el plazo concedido respecto al posible incumplimiento producido.

Son de aplicación directa a las sociedades laborales las normas en materia de ampliación de capital previstas en la LSC, en todo aquello que no se contradiga con el régimen especial previsto para las sociedades laborales en la LSLP. En muchas materias se aplica la LSC (órgano competente, autor/es de la propuesta, convocatoria, modalidades de aumento, etc.) a falta de regulación especial, pero hemos de acudir a la LSLP en cuestiones como la aplicación de las mayorías ordinarias cuando la ampliación tenga por objeto cumplir con los límites establecidos para poder ser sociedad laboral.

En definitiva, existen normas especiales en materia de ampliación de capital en las sociedades laborales cuya aplicación hay que combinar con las normas

\footnotetext{
${ }^{54}$ La reserva especial solo podrá destinarse por la sociedad laboral a la compensación de pérdidas en el caso de que no existan otras reservas disponibles suficientes para este fin, y/o a la adquisición de sus propias acciones o participaciones sociales, que deberán ser enajenadas a favor de los trabajadores de la sociedad con contrato por tiempo indefinido, de acuerdo con lo dispuesto en el art. 12 LSLP (art.14.2 LSLP).
} 
generales recogidas en la LSC de forma que la inscripción de la ampliación no provoque el conocimiento por el Registro Administrativo de las carencias en el régimen de participación en el capital social y con ello se pudiera derivar la perdida de la condición "laboral" de la sociedad.

\section{BIBLIOGRAFIA}

AA.VV, Comentario de la Ley de Sociedades de Capital, Tomo II, Dir. ROJO, A. y BELTRÁN, E., Civitas, Navarra, 2011.

AA.VV., Comentario práctico a la nueva normativa de Gobierno Corporativo. Ley 31/2014, de reforma de la Ley de Sociedades de Capital, Dir. RECALDE CASTELLS, A. y ARIAS VARONA, F.J., Dikynson, 2016.

AA.VV. El régimen jurídico de las sociedades laborales, Aranzadi, Cizur Menor, 2017.

AA.VV. Participación de los trabajadores en la empresa y sociedades laborales, Dir. FAJARDO GARCÍA, G., Tirant lo blanch, Valencia, 2018.

AA.VV. Lecciones de Derecho Mercantil, Volumen I, Dirs. MENÉNDEZ, A. y ROJO, A., Civitas, Cizur Menor, 2013.

AA.VV. Comentarios a la Ley de Sociedades Anónimas, Coord. ARROYO, I. y EMBID, J.M, Tecnos, Madrid, 2009.

AA.VV. Economía Social y Economía Sostenible, Dir. ALFONSO SÁNCHEZ, R., Aranzadi, Cizur Menor, 2010.

AA.VV. Sociedades cotizadas y transparencia en los mercados, Aranzadi, Cizur Menor, 2019.

AA.VV. Introducción al Derecho Mercantil, Dir. VICENT CHULIÁ, F., Tirant lo blach, Valencia, 2012, Versión electrónica, TOL2.727.030

ALONSO LEDESMA, C. "La modificación de los estatutos sociales. Aumento y reducción de capital”, $R d S$, núm. 36, 2011-1.

CABANAS TREJO, R., "Convocatoria y celebración de la junta genera. Junta Universal, Acta Notarial”, Cuadernos de Derecho y Comercio, núm. 68, 2017.

CAÑABATE POZO, R., "Consideraciones sobre el nuevo régimen jurídico de las sociedades laborales: el derecho de separación", Revista Aranzadi Doctrinal, num.10, 2017.

FARIAS BATLLE, M., (“Sociedad participada por los trabajadores. A propósito del régimen de la Ley 44/2015, de sociedades laborales y participadas”, RdS, núm. 53, 2018.

FLAQUER RITUORT, J. “ Breves notas sobre la suscripción incompleta del aumento de capital”, Diario La Ley, núm. 8611, 23 de Septiembre de 2015.

GARCÍA GREWE, C., El derecho de suscripción preferente. Exclusión, inexistencia y configuración estatutaria, Civitas, Navarra, 2014.

HERNANDO CEBRIÁ, L., "Los acuerdos de la Junta General de las sociedades de capital y el interés social: impugnación y otras consideraciones en el entorno de la crisis económica", Revista Jurídica del Notariado, núm. 85, enero-marzo 2013.

LAZARO SÁNCHEZ, E., "Calificación y descalificación de sociedades laborales: coordinación entre el Registro Administrativo y el Registro Mercantil, La Ley Mercantil, núm. 36, mayo 2017. 
MAGRO SERVET, V. "La sociedad de responsabilidad limitada laboral: un modelo societario en progreso", Revista de Derecho Mercantil, num.230, 1998.

MORGADO PANADERO, P., "Las empresas de Economía Social y el Derecho del Trabajo", Rev. Relaciones Laborales, nº 18, quincena 23 sept. al 8 de oct. 2002.

PULGAR ESQUERRA, J., "El acuerdo de la junta de aumento de capital por compensación de créditos en el marco de las sociedades de capital”, RdS, núm. 34, 2010.

TRÍAS SAGNIER, M., "El precio de las acciones en las ampliaciones de capital. Comentarios a la Sentencia de la Sección 15 de la Audiencia Provincial de Barcelona de fecha 4 de junio de 2004 y reflexiones críticas en torno a la línea jurisprudencial del Tribunal Supremo en la materia”, RdS, núm. 25, 2005. 